Manrique-Moreno, N. (2019). La historia y las memorias: el pasado presente en el Claustro de San Agustín de Tunja. Revista de Antropología y Sociología: VIRAJES, 21(2), 39-58. DOI: 10.17151/rasv.2019.21.2.3

\title{
La historia y las memorias: el pasado presente en el Claustro de San Agustín de Tunja
}

\section{NIDIA MANRIQUE-MORENO*}

Recibido: 17 de febrero de 2019

Aprobado: 29 de abril de 2019

Artículo de investigación

\footnotetext{
* Estudiante de Maestría en Patrimonio Cultural. Universidad Pedagógica y Tecnológica de Colombia. E-mail: nmanrimo@banrep.gov.co. (1) ORCID: 0000-0003-1689-2288. Google Scholar.
} 


\title{
Resumen
}

El presente artículo nace como resultado de un proceso de exploración de más de tres años que ha pretendido consolidarse en un proyecto de investigación. Su propósito es reconstruir, a través de la memoria, la etapa de la historia en la que el Claustro de San Agustín de Tunja fue prisión. Esto con el fin de resignificar las representaciones de la espacialidad que históricamente se han erigido alrededor del edificio, especialmente desde la perspectiva del proceso de restauración de los años 80. Estructuralmente, ese análisis de los impactos sociales y los significados atribuidos a la penitenciaría, comenzará con una breve reseña sobre los espacios, tiempos y transformaciones del claustro, para interpretarlos a la luz de los conceptos de patrimonio y de modernidad. La reflexión será enriquecida por la revisión teórica de varios estudios sobre los temas relacionados con el patrimonio, así como por las voces y miradas de personas que estuvieron de algún modo relacionadas con el Panóptico de Tunja, con el fin de tejer una red de lectura del claustro que relacione la historia (heterogénea), el patrimonio tangible y la teoría, con el patrimonio inmaterial y la memoria (viva), que examina la importancia y consumo del patrimonio en el presente, y que se basa en la pervivencia de los recuerdos colectivos e individuales como elementos constructores de identidad.

Palabras clave: Claustro de San Agustín, Panóptico de Tunja, patrimonio; modernidad, memoria viva, patrimonio incómodo.

\section{History and memories: the past is present in the Cloister of San Agustin in Tunja}

\begin{abstract}
This article was originated as a result of an exploration process of more than three years that has sought to be consolidated in a research project. Its purpose is to reconstruct, through memory, the stage of history in which the Cloister of San Agustín in Tunja was a prison, with the aim of signifying the representation of spatiality that historically have been built around the building, especially from the perspective of the restoration process of the 1980's. Structurally, this analysis of the social impact and the meaning attributed to the Penitentiary, begin with a brief review about the spaces, times and transformations of the Cloister to interpret them in the light of the concepts of heritage and modernity. The reflection will be enriched by the theoretical review of several studies on issues related to heritage, and by the voices and perspectives of people who were somehow related to the Tunja Panoptic, in order to weave a net of reading of the Cloister that relates history (heterogeneous), tangible heritage and the theory, with the immaterial heritage and the (living) memory which examines the importance and consumption of heritage in the present, and that is based on the survival of collective and individual memories as building elements of identity.
\end{abstract}

Key words: Cloister of San Agustín, Tunja Panoptic, heritage; modernity, living memory, uncomfortable heritage. 


\section{Introducción}

pesar de que una de las configuraciones ontológicas más

significativas de la modernidad ha sido la percepción general

1 de que el tiempo se esfuma sin esperarnos, sin dejarnos hacer ni ser (Cruz, 2016), el transcurso de medio siglo no parece poco tiempo. La aseveración es dudosa al pensar que se habla del final de un siglo angustioso y el comienzo de uno más inseguro y extraño, en donde los consensos, las tradiciones, las creencias, el arte, el patrimonio y la identidad fueron, y son, fuerzas que, como diría Bauman (2003), son líquidas, y que están impedidas para crear sentimientos de comunidad o sentidos para la acción.

Sin embargo, podemos decir que ese periodo de tiempo es profundamente valioso, cuando pensamos en las dificultades que ofrece el ejercicio de la memoria en una comunidad que - aunque tal vez no se reconozca autónomamente como tal- está vinculada por uno de los lieux de mémoire más importantes que tiene Boyacá: el Claustro de San Agustín de Tunja, en su etapa de penitenciaría, en un intento de reconstrucción realizado por los recuerdos de varias personas, desde sus diversas perspectivas.

Con el propósito de escuchar sus voces y de reconocer sus puntos de vista, se ha utilizado a la entrevista como herramienta de recolección de la información de primera fuente. De esa forma, en 2016 se seleccionaron algunas personas vinculadas a la Penitenciaría de Tunja, con el fin de reconstruir en un tejido plural de memoria, la historia de esta etapa del Claustro de San Agustín. Entre las personas entrevistadas aparece el hombre arrepentido que estuvo preso y recuerda el escenario y la(s) historia(s) de su reclusión, el director de la prisión, el arquitecto practicante que se dio cuenta de la potencial riqueza patrimonial que subyacía en la restauración del claustro, el amigo de un preso que llevaba la goma para el taller de alpargatas del interior del penal, la hija del farmaceuta que recibía en la enfermería a los encarcelados heridos, y otras voces y miradas o focos de memoria, que por distintas razones están conectados con la vida (cuarta vida, cuarto rostro y cuerpo) del claustro.

Esas narrativas personales, familiares y sociales que con dificultad se mantienen 53 años después de que el claustro ha dejado de ser una prisión, permitirán reflexionar alrededor del concepto de memoria, en contraste con el de historia, representado este último por la construcción oficial, acreditada y relativa de lo que podríamos llamar "la tradición" del claustro (Harvey, 2001). Estos análisis y reflexiones, complementados desde múltiples voces, permitirán acercarnos a conceptos como "memoria 
viva", "patrimonio incómodo" y "lugar de memoria". Además, facilitarán una aproximación al análisis sobre cómo la modernidad ha mediado en las grandes transformaciones que ha sufrido el claustro y que además puede explicar varios de los elementos constitutivos de su devenir. Coincidimos entonces con Nora (2009) en que:

Memoria, historia: lejos de ser sinónimos, tomamos conciencia de que todo los opone. La memoria es la vida, siempre encarnada por grupos vivientes y, en ese sentido, está en evolución permanente, abierta a la dialéctica del recuerdo y de la amnesia, inconsciente de sus deformaciones sucesivas, vulnerable a todas las utilizaciones y manipulaciones, capaz de largas latencias y repentinas revitalizaciones. La historia es la reconstrucción siempre problemática e incompleta de lo que ya no es. (p. 21)

En los resultados e intentos de ambos procesos, de la memoria y de la historia, se va cincelando -construyendo y desmantelando- colectivamente la visión heterogénea del claustro. Estas huellas escritas y orales, eruditas y populares, materiales e inmateriales, rurales y urbanas, divinas y profanas, místicas y mundanas se objetivan, de algún modo y en cierto grado, en el ámbito del patrimonio, cuyo fin, entre otros, es el sostenimiento deun pasado, la presencia constante de un pasado, sin el cual no es posible la emergencia y continuidad de la particularidad sociocultural. La preocupación por el patrimonio, entonces, es la urgencia por mantener viva una identidad, una historia de múltiples rostros, que paradójicamente esperan un lugar en la esfera de la diversidad humana.

Es así como el claustro dice lo que fuimos, a partir de lo que deseamos ocultar y mostrar, en una zona siempre ambigua en la que además compaginando con Ricoeur (2004), se disipan las huellas entre lo que la endeble vitalidad de la memoria pierde, en la ausencia y amenaza que es el olvido. Sumado a esto aparece el problema del criterio en nuestros intentos de categorización del patrimonio histórico, que es en otras palabras "el mismo aprieto que nos causa intentar determinar el no-patrimonio" (Castillo, 2007). En esas dificultades de definición, entre la abundancia y la escasez de objetos, monumentos o edificios patrimoniales es clave considerar que el núcleo de esta nueva estrategia de selección no es el objeto per se sino el proceso que le da mérito: la gestión patrimonial con la cual se reconoce la importancia de los legados culturales en el presente.

Para conseguir ese rastreo de la dinámica y no del resultado, se empezará realizando un repaso de la historia del claustro, que puede ser catalogada de zigzagueante, intrépida y cerrada por sus múltiples cambios de rol, que en alguna medida se complementan y se parecen. Se pondrá un 
énfasis especial en la etapa carcelaria que fue la última antes del terremoto de 1967 y de la restauración de los años 80, que le ha permitido pervivir hasta nuestros días.

Luego analizaremos los procesos de conservación, aprovechando el hecho de que en la actualidad el edificio está siendo nuevamente restaurado, para observar aquellos objetos, espacios, relatos y formas que, a la luz de la modernidad, han sido validados como patrimonio que merece ser revitalizado, como parte importante y presentable (en la representación y en el presente) de la identidad sociocultural e histórica de Tunja. En los momentos de análisis que lo requieran, recurriremos a la memoria viva de las personas que conocieron el edificio como cárcel, para que esa mirada plural una los tiempos del lugar analizado y nos permita oír lo que este significa para el habitante de la ciudad que es a quien actualmente le pertenece como patrimonio.

\section{Los tiempos y espacios del Claustro de San Agustín de Tunja}

El Claustro de San Agustín es un edificio de grandes proporciones que hace parte del centro histórico de Tunja. Su construcción se emplazó sobre el Cercado de Quiminza, lugar sagrado y sede del cacicazgo del gobierno de los Zaques, autoridad suprema del pueblo muisca. La obra se inició en 1578 y terminó en 1603 . Tiene por núcleo un jardín de estilo sevillano con cuatro galerías alrededor y una capilla pequeña, en la esquina sureste del predio, con entrada por el Parque Próspero Pinzón.

En 1539 se celebró en este lugar la eucaristía del día de la fundación hispánica de la ciudad, como prólogo de una clara estrategia evangelizadora, que levantó el claustro devoto sobre el anterior cercado indígena, erigiendo una religión nueva sobre el mismo territorio, en una apropiación y transmutación de cosmovisiones y teogonías, de significados míticos profundos y de espacios sagrados que fue tan eficaz como toda la corriente evangelizadora de la colonia a la que pertenece.

Es la herencia de una doctrina religiosa que se ve reflejada en el espacio que funciona como una materialización de formas de pensar, hacer y sentir europeas, trasplantadas en el territorio americano que, si bien poseen características muy similares en su tipología arquitectónica, si se comparan con las del resto del país, tomaron matices muy particulares (como era de esperarse) de acuerdo al carácter de los diferentes poblados a lo largo del territorio nacional: su clima, su gente, su geografía, etc. Esta diferenciación es más evidente con el paso del tiempo, cuando las circunstancias sociales y culturales de cada lugar van transformando el uso del espacio y permiten su adecuación, convirtiéndose los diferentes claustros agustinos del país en 
lugares que, pese a contar con similitudes físicas, son disímiles en sus usos y en sus memorias particulares.

Como el lenguaje verbal no es suficiente para expresar los deseos y los símbolos, la arquitectura ha sido uno de esos lenguajes que usa el hombre para materializarlos, en especial consecuencia con aquello de que "el espacio solo puede ser conquistado a través de la producción de espacio" (Harvey, 1998, p. 285). Los edificios religiosos son libros de piedra, sonidos, mensajes, sensaciones, el claustro es cuerpo de un conjunto de códigos guarecido en unos requisitos de observación activa y paciente. $\mathrm{Al}$ fondo de esa lectura se revela un claustro de herencia medieval, un lugar pensado y construido para cultivar el espíritu, un escenario de adoctrinamiento. No se puede comprender el sentido del claustro sin remembrar al hombre medieval, cargado de culpas, convencido de que debía mirarse hacia adentro para purificarse (Merchensky, 2008). Así es el claustro: un lugar que se abre a lo profundo, que se busca en el silencio, en la apertura hacia el foco, el interior, el patio, en el ancho de los muros, en la penumbra física y anímica de los recintos, en el distanciamiento del centro del que en ese momento era más pueblo que urbe, en la reflexión, en la lejanía de la impureza ordinaria; en fin, en todo aquello que posibilitaba e impedía su cercado espiritual y espacial, hecho compartido por el presente y el pasado.

En su auge, la comunidad agustina recibió el rótulo de misionera y pedagoga del pueblo y el claustro en sí mismo expresa un sistema pedagógico basado en la doctrina religiosa. No es casualidad que dentro de los agustinos más reconocidos se encuentren figuras como Mendel o Lutero, cuyas concepciones religiosas de cierta forma marcaron en otras épocas los usos y formas de apropiación del espacio. Su distancia y reclusión de y en Tunja fue tan sólida y misteriosa que después sirvió de escenario para la aparición de personajes legendarios, como el monje sin cabeza o espanto del panóptico, y de potencias extrañas, ambos muy asociados desde el Medioevo con lo religioso e incontenibles incluso para la modernidad: "Yo sentía energías o presencia de alguien aun sabiendo que estaba absolutamente solo en el predio, sentía que alguien me seguía, que alguien me acompañaba" (Arquitecto Germán Echeverría). 


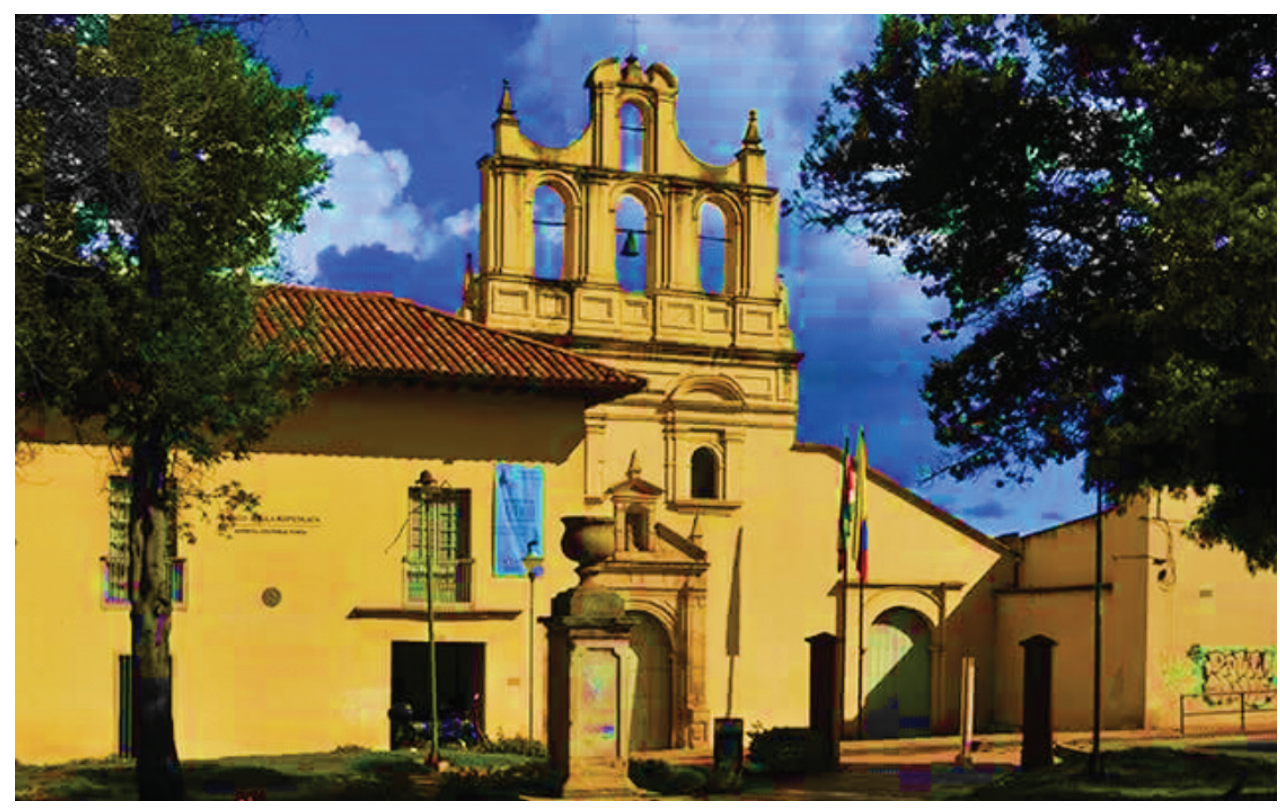

Fotografía 1. Claustro de San Agustín, Tunja.

Fuente: Antonio Castañeda y Banco de la República (2018)

En 1822 los Agustinos tuvieron que entregar la edificación del claustro al Colegio de Boyacá, en razón a la nueva Ley de Educación, que ordenó cerrar los conventos con menos de ocho religiosos, entre los cuales se encontraba el Convento de San Agustín en Tunja (Ocampo-López, 1997). En 1827 se fundó la Universidad de Boyacá, mediante el Decreto del 5 de enero de 1828 del Libertador Simón Bolívar, y se inician sus labores en el mismo año en las instalaciones del Claustro de San Agustín. El claustro pasa nuevamente a los Agustinos entre 1829 y 1831, y el colegio y la universidad son trasladados al Convento de la Compañía de Jesús (Ocampo-López, 1997, p. 189). Bajo la dirección de los religiosos de San Juan de Dios, el claustro se convierte en hospital entre 1824 y 1859. En la guerra civil de 1860 fue habilitado como cuartel del ejército.

A finales de 1862 el claustro pasó a ser propiedad de la nación. A partir de ese momento albergó todo tipo de prisioneros de las diferentes regiones del país, hasta 1966. Es remodelado para ser adecuado a la función de establecimiento de corrección y castigo: las rejas, los cepos, los muros de aislamiento y los demás elementos arquitectónicos que fueron implantados en las transformaciones de esta nueva "ocupación", hicieron que el claustro se convirtiera en un testimonio importante de las dinámicas relacionadas 
con las leyes, condenas, castigos, convivencia entre presos y distribución carcelaria que regían en la época.

La penitenciaría fue erigida por medio de un decreto expedido por el General Sergio Camargo, presidente del Estado de Boyacá, y a pesar de que no cumplía propiamente con los modelos arquitectónicos del panóptico de Bentham, se le conoció desde el principio como Panóptico de Tunja. Ciento tres años después de su creación, y curiosamente uno antes del terremoto de 1967, la cárcel fue trasladada a la vereda El Barne, del municipio de Cómbita (Medina-Flórez, 2007).

El terremoto de Neiva, ocurrido el 9 de febrero de 1967, destruyó un tramo grande de la edificación, que durante más de una década estuvo a merced de la naturaleza, con importantes objetos y aposentos enteros a la intemperie, esperando que en el año 78 -a la voz de posibles reparacionesse empezaran a ejercer las labores de inventariado y de limpieza. La restauración del edificio fue liderada por el arquitecto Álvaro Barrera y llevada a término en 1984. De ahí en adelante el inmueble ha sido sede del área cultural del Banco de la República, adecuándose como biblioteca y como centro de difusión cultural.

Actualmente el claustro hace parte del conjunto de templos coloniales del centro histórico de Tunja que poseen algún espacio público complementario, ya que se encuentra frente al parque Pinzón construido en el siglo XIX como parte de los parques republicanos. Podemos ver entonces cómo la historia del Claustro de San Agustín, la construcción de su(s) espacio(s) y su(s) tiempo(s), se ha venido escribiendo desde hace más de cuatrocientos años; siguiendo el destino de su nombre y su intención de creación, los múltiples oficios y rostros que ha tenido han estado siempre asociados al silencio, a la reflexión, al arrepentimiento y al encierro.

\section{El claustro como patrimonio moderno}

El Ministerio de Cultura ha colocado al Claustro de San Agustín de Tunja en la categoría de Bien de Interés Cultural de la Nación. Indudablemente esta postura institucional está en consonancia con las miradas que los demás agentes activadores del patrimonio han realizado recientemente sobre el edificio. En efecto, siguiendo a Hernández I Martí (2008), podemos afirmar que el claustro ha sido valorado por la sociedad civil, los expertos, el gobierno, los organismos privados y las listas de patrimonio (en este caso del Ministerio de Cultura como agente local). Todos se sienten vinculados en un mayor nivel de pertenencia para con el lugar, sensación bien distinta a lo que ocurría en los años ochenta, cuando el edificio estuvo a punto de arruinarse irreversiblemente por su deterioro 
natural. En ese momento el punto de vista de las personas del común y de la élite política de la ciudad con respecto al claustro era el mismo: el desinterés era vehemente y así lo recuerda la persona que reconoció por primera vez que la restauración era urgente y necesaria:

Tumben esa joda que eso se está cayendo, ese es un rancho viejo, ¿eso

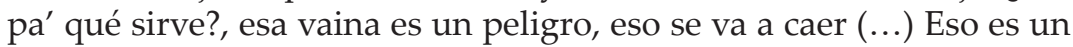
rancho viejo (...) Eso allá secuestraron a no sé quién (...) Eso allá se meten los ladrones. (Arquitecto Germán Echeverría)

El claustro era parte importante solamente en la memoria individual, en el tiempo subjetivo (Assman, 2008), de las personas que conocían la cárcel al tener relación directa con un preso o un oficio específico asociado al penal: "pasaba y veía en ruinas y decía 'qué tristeza que se acabe un monumento de estos"' (José María Aponte, exalcalde, amigo de un recluso).

El gran logro de la restauración de los 80 no solamente es material, sobre la estructura del inmueble, sino también intangible: la obra pudo convencer a los tunjanos de que el claustro era verdaderamente un lugar importante, ya no solo meritorio de un puesto en la memoria de algunos individuos sino de reconocimiento especial en la historia de todo el país. Ya que además compartía el sigma católico de la colonia (convento), el decimonónico interés continental por la educación (colegio y universidad) y los procesos de violencia bipartidista (cuartel); por otra parte, reconocía valores especiales en la identidad del pueblo tunjano, mostrables e incómodos respectivamente para la auto-representación de su pasado (Harvey, 2001): cierto apogeo hispánico en los murales coloniales y una mazmorra que era terrible desde la gelidez del edificio hasta las formas de tortura. Así fue convirtiéndose en un escenario sobre el que recaía el peso de la memoria cultural, en todos los alcances que Assman (2008) relaciona con ese nivel de memoria y de identidad: desde lo cultural, lo histórico y lo mítico.

Los ciudadanos de ese presente y nuestros contemporáneos reconocen que el claustro, como entidad patrimonial, recopila las cenizas de un orden anterior devastado o absorbido, así como las marcas, lugares, objetos y demás asuntos de un orden que ya prevalecía (Duverger, 2007), y que aparecen bien secuenciados en la línea de tiempo, como en el reconocimiento geológico de las edades de la tierra: una estación indígena subyugada, desaparecida en el mundo abisal del pasado remoto del lugar, sobre la que se incrustan dos formas encerradas de las entidades dominantes: las fuerzas eclesiásticas y las militares, sobre cuyos laureles se erige un nuevo ciclo (el carcelario) también denostado por la moralidad y la devoción, por el predominio de lo 
bueno y lo puro como monumento memorable, en la ceremonia ortodoxa de la tradición y sus restauraciones.

Como acto, la centuria en la que el claustro fue panóptico destradicionaliza el tejido histórico que aquel iba hilando: la imagen de la cárcel aparece como una decadencia que paradójicamente debe ser entendida como el origen de su modernización. El teocentrismo medieval al que se pareció la misión conquistadora fue perdurable y poderoso, y ubica a la perfección a nuestro claustro religioso y también a su etapa castrense (castrum, recinto fortificado; castus, puro, alejado de vicios) en el marco del proceso colonizador de lo que hoy conocemos como América Latina. Sin ahondar en extremo en este asunto, podemos mencionar que la configuración progresiva de poderes centrales en la organización social, política, económica y cultural, ubicó a la iglesia y al estamento militar en el centro de las principales determinaciones existenciales de la gran mayoría de las "naciones latinoamericanas" (Tirado-Mejía, 2003).

La modernidad es la razón, la ciencia, la lógica, el progreso. Solamente la necesidad de corrección, aislamiento, control, vigilancia y regeneración (Foucault, 2002), y el interés educativo en la reformación de los que habían perdido aquella senda, acercaron al claustro las luces de la modernidad, en la imposición de correctivos a sus inobediencias. A pesar de esto, en una ciudad tan conservadora y medrosa como Tunja, la llegada de la modernidad tuvo que hacer pactos que implicaban el mantenimiento de un orden prestablecido. Es así como estas lógicas maniqueas de encierro y de castigo, estaban asociadas casi siempre con el catolicismo, en símbolos como el nazareno crucificado y los diez mandamientos, y en mensajes aleccionadores con que se presionaba moralmente a los presos: "Para el ojo de Dios no hay tinieblas: jimpuro, Dios es tu testigo!"; “No hay peor compañero que la mala conciencia."; "Puso Dios en el fondo del trabajo un tesoro inestimable: la tranquilidad" (Rubio y Briceño, 1909).

Una construcción que termina siendo mixta, y maravillosa en sus paradojas, complementos y contradicciones, desde los materiales de su reconstrucción (originales de los vestigios y adaptados) hasta la intención de la transformación y la conservación: hecha con las poéticas ruinas de John Ruskin, y con las mejoras innovadoras de Viollet-le-duc (GonzálezVaras, 2014). Desde lo claro y lo oscuro, del ejemplar asceta y el reprochable reo, la pintura presidiaria y la colonial, encierro místico y encierro punitivo, solo ha empezado a ser valorada en su totalidad recientemente. Después de la cercanía al deterioro absoluto y de la remodelación que apreció sobre todo la tradición ortodoxa del claustro, llegamos a un momento que juzga y modifica el pasado para poder aceptarlo, disfrutarlo y "consumirlo" 
en el presente, tal vez ya intentando superar la peligrosa puerta hacia el juicio moral de la historia (Castillo, 2007).

\section{El patrimonio y el fracaso del proyecto de modernidad}

El proyecto de modernidad esbozado por los pensadores de la Ilustración proponía el surgimiento de una ciencia objetiva, una moral positiva y una ley universal que emanciparan a la humanidad del terror a lo desconocido, atribuido a lo irracional, lo mitológico y lo religioso (Adorno y Horkheimer, 1994). La modernidad se construyó en torno a los ideales de explicación racional de la realidad: progreso lineal, descubrimiento de verdades abstractas universales y especialización progresiva del conocimiento, condensados en metarrelatos que intentaban interpretar y explicar la realidad (el marxismo, el psicoanálisis, el liberalismo, el idealismo, los totalitarismos). Sin embargo, el proyecto de la Ilustración se destruyó a sí mismo, cuando la lógica que apelaba al dominio absoluto y a la manipulación efectiva de la realidad se extendió hacia el control de las personas a través de una descollante tecnología de dominación de los seres humanos. De esta manera el optimismo delirante de los siglos XVIII y XIX llegó a sus últimas consecuencias en el XX, dando origen a un nacionalismo exacerbado, representado por el terror de los campos de concentración, de las escuelas de muerte, de las guerras mundiales y el exterminio nuclear (Harvey, 1998).

Estas crisis globales dieron fundamento a los movimientos de contracultura de los años sesenta y fueron el origen de la época posmoderna que vivimos actualmente. Dos ejemplos bastarían para argumentar la relación que estamos aludiendo: la defensa a ultranza de la herencia aria y del pasado imperial romano-germánico de la Alemania nazi, y la obsesión de Mussolini por restablecer el orden del imperio romano sobre sus ruinas arquitectónicas. Esas miradas exaltadas del pasado y de la conservación hicieron necesario reestructurar la noción de patrimonio y sus objetivos, partiendo de las críticas y planteamientos que en su contra ha esgrimido la modernidad globalizada, y que le han dado apertura a nuevos elementos de estudio e incluso a ejercicios disciplinares que vinculan a las ya consagradas historia, geografía, antropología, sociología, con la filosofía, la psicología y el turismo, en los estudios sobre la memoria, el olvido y el tiempo, la autenticidad de los monumentos consagrados, y la invasión del sistema de mercado en todos los campos de la actividad humana (Urbano de Carvalho, 2017). 
Por ahora profundicemos un poco esa relación entre el patrimonio cultural, la sociedad y la historia. De acuerdo con Ballart y Tresserras (2001) el patrimonio se entiende como el conjunto de bienes materiales e inmateriales que conmemoran un acto valioso que transcurrió en el pasado pero que se vincula con el presente y el futuro, relacionando así distintas generaciones, lo que contribuye a que un colectivo determinado se reconozca a sí mismo en su diferencia, en su oposición a los otros; es decir, construya una identidad gracias a dicho patrimonio. En este orden de ideas, el patrimonio es el resultado de un proceso cultural en cuanto que son prácticas que involucran una serie de significados de interpretación colectiva. Así, el patrimonio sería un instrumento de la cultura a través del cual se imponen normas de producción cultural, se adapta a los individuos a una estructura económica y política arbitraria y se legitiman sus estructuras perceptivas (García- Canclini, 1982), en ámbitos y modelos tan complejos como los de la escuela.

Se puede afirmar, entonces, que el patrimonio ha sido un instrumento para fundamentar y perpetuar un orden de desigualdad y dominación sobre los individuos. Desde esta perspectiva puede explicarse el hecho de que el lugar de memoria que estamos abordando, sea admirado de manera especial en su función más ligada a ese orden, la etapa en que el orden católico o religioso se sirvió de este espacio: cuando fue convento agustino. Esto en contraste con la etapa penitenciaria que es la más alejada, la menos memorable, a los ojos de algunos de los arquitectos que dirigieron la restauración iniciada en los años 80. Así mismo, don José María Aponte, quien fuera alcalde de Tunja en esa misma época, se refiere al tema de la restauración con la autoridad de un arquitecto retirado y con el amor de un tunjano encariñado con su ciudad: "No creo que sea importante [que la etapa penitenciaria del edificio sea tenida en cuenta en la restauración] porque no tenía ningún valor arquitectónico comparado con el valor que tiene el claustro".

\section{La modernidad globalizada y las nuevas lecturas del patrimonio}

En 1822 los frailes agustinos de Tunja dejaron el claustro. Este hecho coincide con dos grandes eventos históricos: la ayuda que pidió Fernando VII a la Santa Alianza para derrocar al trienio liberal que había depuesto su monarquía dos años antes, y el nacimiento de los Estados-nación en América Latina por medio del cual empezábamos a dejar de ser una colonia. Ambos marcaron la inestabilidad de la dinastía europea, y se convirtieron en los primeros atisbos de modernidad en la patria y el claustro. Ese momento histórico fue muy parecido a la exigencia que "los presentes del pasado" 
enfrentan al hilvanar el desarrollo de su identidad, en esa "voluntad de perpetuación de la memoria" que se asocia a un monumento patrimonial (González-Varas, 2014) o, en otras palabras, la tarea de conservar lo que algunos actores han estimado como patrimonio en un contexto social y cultural determinado.

Esa interpretación hacedora del pasado puede llegar a ser "ligada a un mo(nu)mento específico" tan profunda que hace que la imagen actual del mismo pueda ser insignificante, carecer de sentido, como parece suceder, por ejemplo, en el dominio que ejerce la memoria de las personas entrevistadas por encima de su consciencia del presente, cuando manifiestan inseguros que no han ido al Claustro de San Agustín recientemente y que ignoran cuáles son sus funciones hoy en día.

La modernidad trajo consigo "un nuevo orden del tiempo y una nueva estructura social e ideológica a las que acompaña esta nueva cultura del culto a los monumentos, de la preservación de las ciudades históricas, de la institucionalización del patrimonio cultural" (González-Varas, 2014, p. 9). Es evidente la presencia latente de una nueva manera de ver el tiempo: las miras estaban puestas en el futuro, así como las esperanzas, ese optimismo establecía un régimen de la historicidad, en el que no era el pasado una consagración gloriosa sino una referencia, un ejemplo aleccionador, una colección de versiones de la humanidad que con sus logros y errores permitirían perfeccionar el proyecto de lo venidero. Esas nuevas consideraciones de lo temporal implicaban también una relación nueva con el espacio, más significativa y aprovechable en el marco de la sociedad globalizada: había que darle materia al tiempo y escenificar las identidades y los pasados que fuera, como fundacionalmente observó Alois Reigl, un fervor cultural por los monumentos.

Lo que podríamos llamar "primera modernidad" utilizó al patrimonio como un sustento de la identidad nacional, que degeneró en un hipernacionalismo cuyo fin último era el dominio absoluto del ser humano. La segunda "caracterizada por la consolidación del capitalismo y las aperturas socioculturales de la globalización" lo redujo a un mero espectáculo destinado a satisfacer las necesidades de entretenimiento creadas por los medios de comunicación, negándole así su carácter de profundidad capaz de responder a las necesidades íntimas del ser humano (Vera, 2003).

Como hemos venido diciendo, su interpretación selectiva, cambiante en las divergencias de las generaciones, constituía una representación profunda (ontológica en términos de Hernández I Martí) del ser individual y nacional de una cultura, manifiesta tanto en sus reproducciones artesanales y artísticas, como en los engranajes de su vida social. El gran salto en la modernidad es mercantilista: el negocio del turismo se aprovechó de la 
excelsitud del espacio (cultural y natural) para meter al patrimonio en los mecanismos del sistema de consumo. El pasado dotado de sentido para el presente, en la cimentación de las identidades, se hizo venable.

Pongamos en situación el caso específico del Claustro de San Agustín. En este momento de la disertación debemos preguntarnos: “¿de qué modo se presentan y se explican los edificios antiguos al abrirlos al público, y los objetos al exhibirlos en los museos?". Siguiendo a García-Canclini (1999), podemos conjeturar si será casual que la versión carcelaria del claustro, y sus otras funciones menores, hayan sido devaluadas por la restauración arquitectónica ante la deslumbrante etapa colonial, por el hecho de que sus rasgos, funciones y relatos fueron producidos y se conmemoran hoy como importantes por una minoría popular, distanciada de cualquier prestigio político o económico.

En efecto, a partir de una serie de testimonios, fotografías, vestigios y documentos se ha podido establecer que el periodo de cárcel pareció poco significativo para ser tenido en cuenta en el proceso de restauración, por lo que se blanquearon paredes (testigos de la vida en la cárcel), se derribaron celdas, se reubicaron rejas, desaparecieron las huellas de los castigos mientras se rescataba la pintura mural del siglo XVII y XVIII. Durante la restauración del claustro se corrigió un "patrimonio incómodo, disonante o indeseado" (Ashworth y Tunbridge, 1996), se intentó minimizar, suavizar y embellecer una herencia molesta.

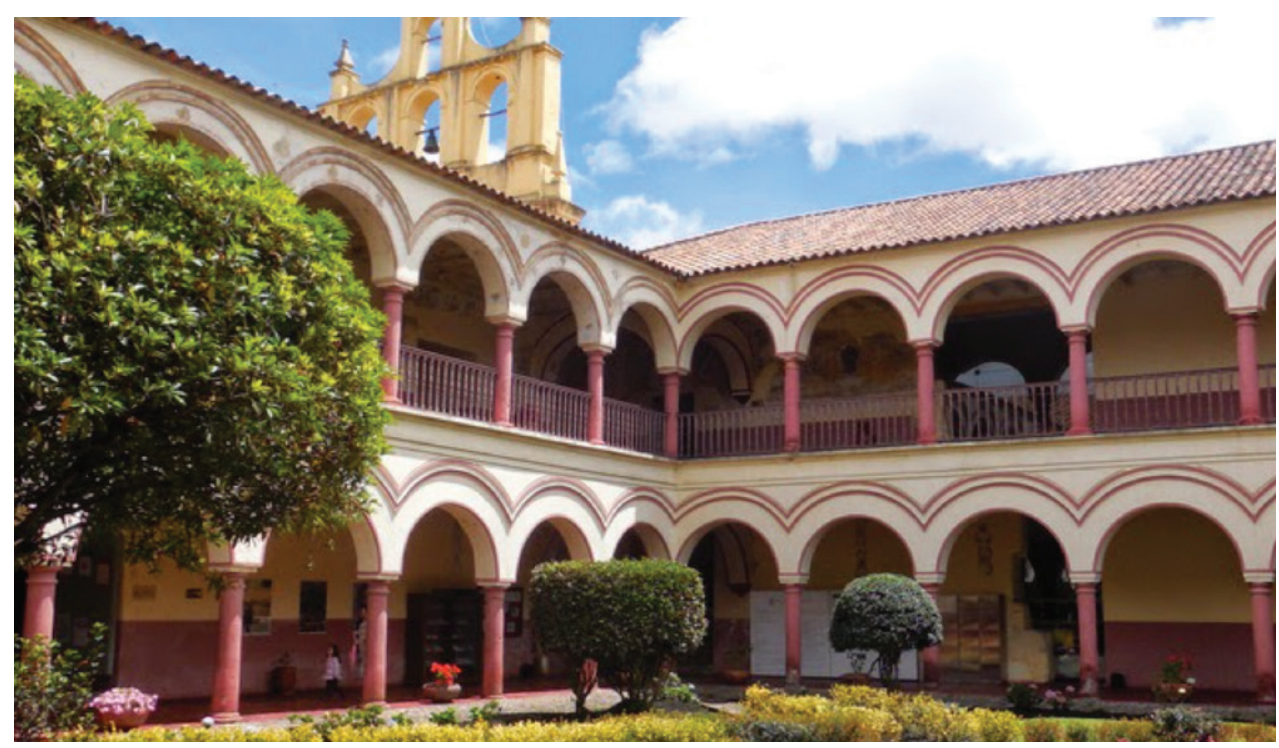

Fotografía 2. Foto sin título 8 (Fotografía hallada sin datos de autor ni de propiedad). Fuente: Tomada de Historia del claustro San Agustín en la ciudad de Tunja (2015). 
Desde la literatura, escritores como Medina-Flórez (2007), Salamanca (1939), Dorta (1942) y Ocampo-López (1997) han hecho una descripción del panóptico solamente desde su arquitectura y desde las sensaciones que generaba el lugar. Vale la pena controvertir los relatos conservadores y conservacionistas de la visión tradicional de este patrimonio y cotejar con la memoria de los que habitaron y usaron este espacio con el fin de aproximarnos al sentido de la existencia de la cárcel desde los recuerdos, archivos, monumentos, pinturas murales, prensa, etc. Verdaderamente vale la pena revitalizar ese patrimonio a partir de la reconstrucción de la memoria viva de algunos testigos, las emociones estimuladas por las celdas de castigo, por las dificultades de convivencia, la diversidad de los castigos y las costumbres, la laboriosidad de los talleres de trabajo y todas las demás narrativas que giran alrededor de esas formas del pasado también merecen ser contados, resignificados hacia el futuro, en una conservación del escenario (del que quedan físicamente seis celdas, en función de testigos), pero también de lo intangible.

Es preciso reconocer el "espíritu del lugar (el conjunto de memorias, técnicas, conocimientos) que le dan sentido, valor, emoción y misterio" (ICOMOS, 2008), reconocer, en suma, el patrimonio inmaterial, enriquecido, por ejemplo, por una gama de auténticas emociones escritas por algunos presos y borradas por la pintura y por el tiempo, o de sensaciones intencionadas que varían de la humillación sancionadora ( $S i$ sufres injusticias consuélate, pues es más desgraciado quien la comete), a la ilusión arrepentida ( No vienes a morir! si la esperanza! / Traes de ser al fin rehabilitado) (Rubio y Briceño, 1909), pasando por la posibilidad real de que un sujeto sea "anulado" socialmente, como sus propios, vulnerables recuerdos, por no cumplir con un modelo social impuesto:

Para los vecinos y amigos eso fue un escándalo, pero no en el pueblo, en una vereda, esa gente es muerta, fue muy triste, muy duro, sobre todo el odio, todo el mundo me miraban como a cualquier basura después de volver de la cárcel. (Don José Santos, 86 años, persona recluida en el Panóptico de Tunja, entre los años 1956 y 1958)

Desde la concepción moderna, el Claustro de San Agustín sufrió una restauración selectiva en cuanto se invisibilizó su uso penitenciario y se retornó a una percepción de lo que supuestamente sí era patrimonial, es decir, a su estado primigenio. Antes del proceso de restauración se perdieron testimonios materiales de lo que era la vida en prisión dándole la espalda completamente al espíritu del lugar: "En la celda de las mujeres había testigos, mechones de pelos en la pared, poesías escritas, refranes, 
recortes de revista Cromos, lamentos, contaban sus vidas, eso era patrimonio gráfico" (Arquitecto Germán Echeverría).

El cambio de función quizás indicó un cambio de prioridad que no encarna una ruptura absoluta con el pasado pues este se percibe allí mismo, en la memoria, que para nuestro caso, es de múltiples rostros, y por ende de múltiples silencios y olvidos, donde la necesidad de su restauración oscila entre el descuido (muchas veces parecido al desprecio) y la necesidad de construir un material que asegure identidad, historia y singularidad.

\section{Restos, conclusiones y retos}

El Claustro de San Agustín es una convergencia que sí puede suceder armónicamente. De la misma forma como convivieron la angustia y los sistemas de represión y encierro de los presos: "un espectáculo de miseria, desaseo, estrechez, ruinas" (Bruno, 1936), con el pánico que causaban los personajes fantasmagóricos de las leyendas locales; o en una compartida función del suelo de tierra del edificio, queen dos épocas distintas sirvió como ocultador de huesos: en una de sus figuraciones más recientes del horror con posibles homicidios y enterramientos por reyertas entre presos (según arguye don Álvaro, constructor artesanal que participó en la restauración de los 80), y en una de las metas iniciales del claustro, de servir como lugar de sepultura de la familia de doña Ana de Otálora (1621), compartiendo con los padres agustinianos una posibilidad reglamentada por una bula de 1586, del papa Sixto V (Paniagua, 2001), que fue curiosamente el gran restaurador del patrimonio -urbis restaurator-de la Roma de la Contrarreforma. Esa serie de paradojas y de juegos de la historia hacen que el tiempo se mantenga heterogéneo y plural como podría también serlo la manera de conservar, observar y entender al Claustro de San Agustín en la actualidad.

Así, teniendo en cuenta todos los elementos referenciados, el patrimonio que se objetiva en el Claustro de San Agustín cuenta con procesos de larga duración, definitivos para las dinámicas de identidad, no solo de Tunja, sino también del país. El patrimonio indicado revela recorridos y huellas que en las instituciones y la dinámica del Estado colombiano cobijan, ante todo, luchas por la permanencia espaciotemporal, que sería, en términos de Max Weber (1977), el fin sustantivo de las comunidades políticas, en tanto que en ellas se definen espacios y dinámicas de poder visibles en ciertos lugares, a partir de transformaciones y persistencias históricas regionales y nacionales.

Claustro, universidad, cuartel, hospital, cárcel, biblioteca y archivo, todas estas instancias "funden ya no solo formas muertas y formas vivas de la cultura en la esencia híbrida e impura del patrimonio", 
sino que también están aseguradas por mucho tiempo al devenir histórico en bienes e historias que han sido "reciclados, adaptados, refuncionalizados, redituados, revitalizados, reconstruidos o reinventados en un contexto de modernidad" (Hernández, 2008, p. 27). Nuestro patrimonio cultural e histórico ha servido para reproducir algunas consideraciones hegemónicas muchas veces discriminatorias, que por ejemplo están lejos de compartir la producción cultural de la ruralidad y del obrero. La restauración actual del claustro es una oportunidad para que la pluralidad de voces y rostros que convergen alrededor de este lugar de memoria, que está vivo en la identidad de varias personas y que históricamente ha sido catalogado como "incómodo", desvirtuado, ignorado y olvidado, sea percibida e interpretada libremente por los espectadores y restauradores del futuro, en marcos culturales distintos: receptores minimalistas o compiladores incansables.

Estas observaciones pueden incluso admitir una comparación biológica: los animales garantizan la supervivencia de sus rasgos mediante la información genética transmitida por el ADN. En el caso del ser humano, el proceso es más complejo pues además de los rasgos genéticos, los hombres heredan sistemas simbólicos para conservar un legado a través del tiempo. Pensando en el futuro, las restauraciones que hoy vive el Claustro de San Agustín nos permiten soñar con que este tiene la posibilidad de conciliar las subordinadas memorias de los olvidados, los relegados y los marginados, con la tradición del arte y la moral de sus estamentos consagrados, en una misma casa de patrimonio para bien de sus usuarios en el presente quienes además (como lo piden varios grandes teóricos del patrimonio) obtienen, de y en un edificio arcaico, un beneficio directamente relacionado con sus necesidades reales y actuales en la función educativa y cultural que la biblioteca del claustro ejerce, y que se ha venido consolidando en los últimos años como un espacio reconocido de aprendizaje y de lectura individual y colectiva. Este logro se complementa también con el hecho literal de que la historia es una maestra colosal, verificable en la visita que hacen estudiantes de arquitectura a las decisiones visibles que se tomaron en la restauración del inmueble en los años 80: el pasado, como a ellos, nos enseña a imaginar las formas y a concretar los materiales con los que puede consolidarse lo venidero.

Cualquiermonumento oedificiocuyo propósito sea eldedar testimonio del paso del hombre por el espacio y por el tiempo, inevitablemente va siempre a decirnos algo sobre lo que seremos. Nuestras interpretaciones de sus sonidos y silencios son aquellos "elementos destinados a reemplazar las partes inexistentes" que "deben integrarse armoniosamente en el conjunto, distinguiéndose claramente de las originales, a fin de que la restauración no falsifique el documento artístico o histórico" (ICOMOS, 1964). 
Las dificultades de esa armonía imposible, el hecho - a veces salvador y a veces reprochable - de que por las puertas del turismo el patrimonio ya pertenezca a las dinámicas del mercado (obsolescencia programada y utilitarismo), en las que todo ha de servir para algo (González-Varas, 2014), y con todas las dificultades que el ejercicio crítico de este artículo ha impuesto sobre el discurso hegemónico del claustro y en favor de la memoria viva, este lugar sigue siendo un espacio-tiempo enternecedor en la simpleza de unos pasillos y de un patio, y seductoramente complejo vigía de parte imprescindible de nuestra identidad, sigue siendo un lugar de memoria que como todos "pertenece a dos reinos, lo que le confiere interés, pero también complejidad: simples y ambiguos, naturales y artificiales, abiertos inmediatamente a la experiencia más sensible $y$, al mismo tiempo, fruto de la elaboración más abstracta" (Nora, 2009, p. 32).

El Claustro de San Agustín ha tomado sentido como una fuente de posibilidades y desafíos ante la configuración del ser del individuo partiendo de las diversas respuestas que se han cristalizado dentro de sus muros, las cuales van desde la austeridad del monje, la disciplina del estudiante, la valentía del soldado y el arrepentimiento del preso hasta la instrucción del bibliotecario, todas ellas respuestas ante la angustiosa pregunta por lo que somos, sobre todo a partir de nuestra relación con el otro. Tanto los elementos físicos que hacen parte de la edificación, como las dinámicas sociales que allí se dieron durante toda su historia, representan la identidad del pueblo de Tunja.

Eso nos lleva a considerar, solo como ejemplos representativos, las lógicas de confianza en la relación preso-guardia que eran retribuidas con la permanencia en celdas menos terribles; la luz del sol que se negaba a dejarse ver en los peores lugares, comportándose con la misma repulsión que los presos más violentos; las sesenta y tres celdas comunes y las seis de castigo; los períodos de escuela, de hospital y cuartel también pueden compartir espacio y tiempo en la idea de "hacer convivir lo antiguo con lo actual, dinamizar el bien, proyectarlo en el tiempo, darle nueva vida" (Barrera, 2003) en un patrimonio que ha funcionado como un multiverso, que puede salir de su condena de "haber sufrido a lo largo de la historia un sinnúmero de agresiones" (Vallín, 1998), si y solo si consideramos que sus memorias están vivas, ya que las nuevas restauraciones son una oportunidad para evitar que estas vayan a "donde hay que descender por escalones que tienen por centro un gran poste de cadenas", allá "en el extremo del callejón donde hay una pieza honda y muy húmeda, llamada El Olvido" (Rubio y Briceño, 1909). 


\section{Referencias bibliográficas}

Adorno, T. y Horkheimer, M. (1994). Dialéctica de la Ilustración: Fragmentos Filosóficos. Madrid: Trotta.

Castañeda, A. y Banco de la República. (2018). El Banco de la República inicia la restauración del Claustro de San Agustín de Tunja [Fotografía]. Banco de la República. Recuperado de https://www.banrepcultural.org/noticias/el-banco-de-la-republica-inicia-larestauracion-del-claustro-de-san-agustin-de-tunja

Ashworth, G.J. y Tunbridge, J.E. (1996). Dissonant Heritage: The Management of the Past as a Resource in Conflict. Chichester, England: Wiley.

Assman, J. (1988). Collective memory and cultural identity. En J. Assmann \& T. Hölscher (eds.), Kultur und Gedächtnis (pp. 9-19). Frankfurt: Suhrkamp.

Assman, J. (2008). Communicative and Cultural Memory. En A. Eril \& A. Nünning (eds.), Cultural Memory Studies. An international and Interdisciplinary Handbook (pp. 109-118). New York/Berlin: de Gruyter.

Ballart, H. y Tresserras, J. (2001). Gestión del Patrimonio Cultural. Barcelona: Ariel.

Barrera, Á. (2003). Arquitectura y Restauración. Bogotá: Villegas Editores.

Bauman, Z. (2003). Modernidad Líquida. Buenos Aires: Fondo de Cultura Económica.

Bruno, F. (1936). La reforma carcelaria y penitenciaria en Colombia. Exposición del director de prisiones Dr. Francisco Bruno al ministro de gobierno Docto Alberto Lleras Camargo. Bogotá: Departamento de prisiones. Imprenta Nacional.

Castillo, J. (2007). El futuro del patrimonio histórico: la patrimonialización del hombre. e r rph Revista Electrónica de Patrimonio Histórico. (1). Recuperado de https://dialnet.unirioja.es/ descarga/articulo/4012918.pdf

Cruz, M. (2016). Ser sin tiempo. Barcelona: Herder.

Dorta, E. (1942). La arquitectura del renacimiento en Tunja. Madrid: Yagues.

Duverger, C. (2007). El primer mestizaje. La clave para entender el pasado mesoamericano. Ciudad de México: Taurus.

Foucault, M. (2002). Vigilar y castigar: nacimiento de la prisión. Buenos Aires: Siglo XXI Editores.

García-Canclini, N. (1982). Las culturas populares del capitalismo. México: Editorial Nueva Imagen.

García-Canclini, N. (1999). Los usos sociales del Patrimonio Cultural. En C. Aguilar (ed.), Patrimonio Etnológico. Nuevas perspectivas de estudio (pp. 16-33). Sevilla: Consejería de Cultura. Junta de Andalucía.

González-Varas, I. (2014). Las ruinas de la memoria: ideas y conceptos para una (im)posible teoría del patrimonio cultural. México: Siglo XXI Editores.

Harvey, D.C. (1998). La condición de la posmodernidad. Investigación sobre los orígenes del cambio cultural. Buenos Aires: Amorrortu Editores.

Harvey, D.C. (2001). Heritage Pasts and Heritage Presents: temporality, meaning and the scope of heritage studies. International Journal of Heritage Studies, 7(4), 319-338.

Hernández I Martí, G.M. (2008). Un zombi de la modernidad: el patrimonio cultural y sus límites. La Torre del Virrey: Revista de Estudios Culturales, (5), 27-38.

Historia del Claustro san Agustín en la ciudad de Tunja. (26 de mayo de 2015). Historia del Parque Pinzon y el Claustro de San Agustin [Mensaje en un blog] [Fotografía 2]. Recuperado de http://hparquepinzonclaustrosanagustin.blogspot.com/

ICOMOS. (1964). Carta internacional sobre la conservación y la restauración de monumentos y sitios (Carta de Venecia). II Congreso Internacional de Arquitectos y Técnicos de Monumentos históricos, Venecia. 
ICOMOS. (2008). Carta ICOMOS para Interpretación y Presentación de Sitios de Patrimonio Cultural. $16^{\underline{a}}$ Asamblea General del ICOMOS, Québec, Canadá.

Medina-Flórez, E. (2007). Costumbres tunjanas del siglo XX. Tunja: Alcaldía Mayor de Tunja, Secretaría de Cultura y Turismo.

Merchensky, V. (2008). Las ataduras de la conciencia medieval. Buenos Aires: Tantalina. Recuperado de http://tantatinta.com/articles/4

Nora, P. (2009). Les lieux de memorie (Laura Maselli, trad.). Santiago: LOM Ediciones, Trilce.

Ocampo-López, J. (1997). Tunja: Cuna y taller de la libertad. Alcaldía Mayor de Tunja. Cátedra de Tunja: Editorial Talleres Gráficos Ltda.

Paniagua, J. (2001). Magne Pater Augustine: la exaltación agustiniana en las pinturas del convento de Tunja. Archivo Agustiniano, 85(203), 193-229.

Ricoeur, P. (2004). La memoria, la historia, el olvido. Buenos Aires: Fondo de Cultura Económica de Argentina.

Rubio, O. y Briceño, M. (1909). Tunja desde su fundación hasta la época presente. Miembros de la Academia de Historia de Bogotá. Bogotá: Imprenta Eléctrica.

Salamanca, R. (1939). Guía histórica ilustrada de Tunja 1539-1939. Bogotá: Escuelas gráficas salesianas.

Tirado-Mejía, Á. (2003). Estado y política en el siglo XIX. Bogotá: Norma.

Urbano de Carvalho, H. (2017). Patrimonio y modernidad. Lima: Turismo y Patrimonio. Recuperado de http://ojs.revistaturismoypatrimonio.com/index.php/typ/article/view/41.

Vallín, R. (1998). Imágenes bajo cal \& pañete. Pintura Mural en Colombia. Con la colaboración de Clemencia Arango. Bogotá: Museo de Arte Moderno.

Vera, J.A. (2006). Segunda modernidad y sociedad de riesgo. Toluca Revista Convergencia, 13(40).

Weber, M. (1977). Estructuras de poder. Buenos Aires: La pléyade. 